BRTtSH MEDICAL JOURNAL VoLUME $288 \quad 21$ JANUARY 1984 PRACTICE OBSERVED

\section{Minimum Standards for Training}

\section{Selecting general practitioner trainers}

D J PEREIRA GRAY

General practice differs from all other branches of medicine in
accepting the principle that teaching is a privilege, which has

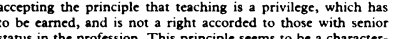

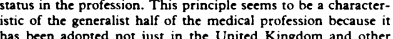

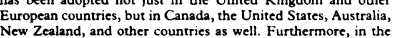
New Zealand, and other countries as well. Furthermore, in the
United Kingdom teaching privileges once granted are subject

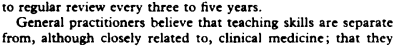
from, although closely related to, clinical medicines that they
require additional time to learn ; and that time spent in teaching

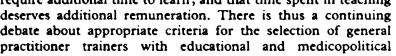

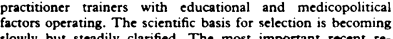

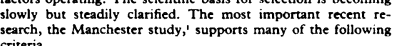

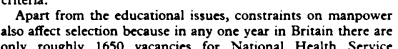

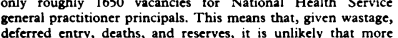

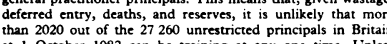

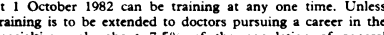

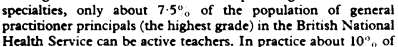

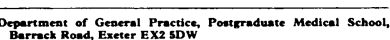

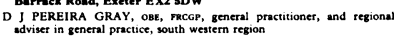

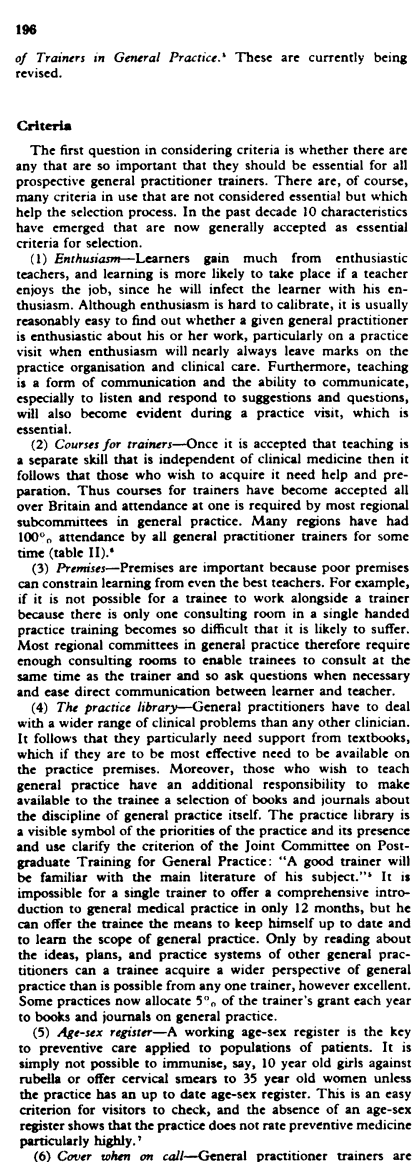

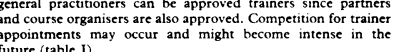

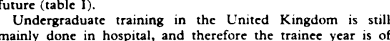
ce. This has been underlined by trainces,

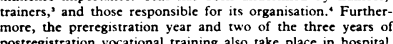

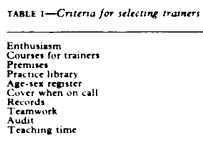

The trainec year provides the only serious opportunity for
doctors to learn the principles of personal, primary, preventive,

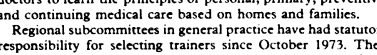

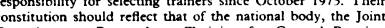

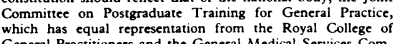
mitrecs (the local medical commintees) with others, such as

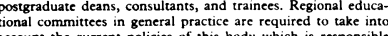

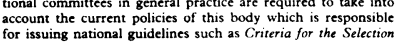

BRTITHH MEDICAL JOLRNAL VOLLME $288 \quad 21$ JANUARY 1984 required to provide permanent cover for trainess working in
the practice. This means hat when on call a trainee should be able to get in touch with either the crainer or a named principal
without difficulty. The traines should know who w to ring and

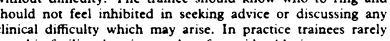

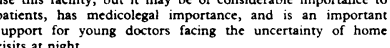
Mists at night.
(7) Recordse -The importance of organised medical records
has been one of the main features of standard setting in general

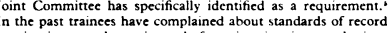
kecping in general practice and of wasting time in consultations
tryyng to get the papers into order. The Joint Committre now requires that continuation cards and all hospiatial recerds and invesigazations should be attached in chronological order. This
means that traines can sec continuity of general pracctitioner

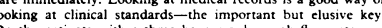
Do he patients with asthma have regular peak how rates 5 .

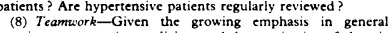
(8) Teamuork-Given chice growing emphasis in gencral
practice on preventivive medicine '2nd the monitoring of chronic discase, the importance of doctors learning to work in teams in
dienera he

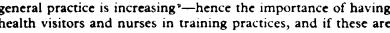

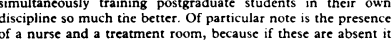

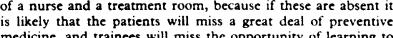

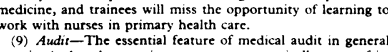
practice is that the practice measures systrematically some of itit clinical and organisational activities. This leads the practice
inevitably into setting aims or targets as well as evaluation. Sir George Pickering emphasised this feature of medical audit.

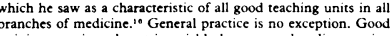

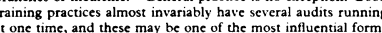

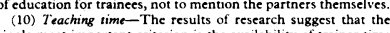
single most important criterion is the avaiability of trainer time payment for the time provided by the trainer and the e ther hal
for the responsibility of education rand organisation The

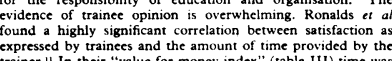
xxpressed by traineces and the amoun of time provided by the
trainer." In their "value for money index" (table III) time was the single most important factor, and 94", of trainees receiving
four hours or more teaching a week considered their trainer our hours or more teaching a week
was giving value tor money in terms of training. In some eregion

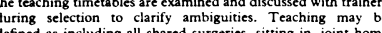
visits, random case and problem case analysis and weckly
tutorials. Many training practices provide more time than this

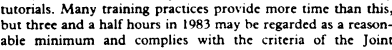
Discussio

When considering criteria for selecting trainers it is i important
to realise that standards in general practice are not satic but

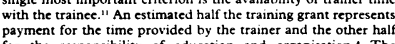

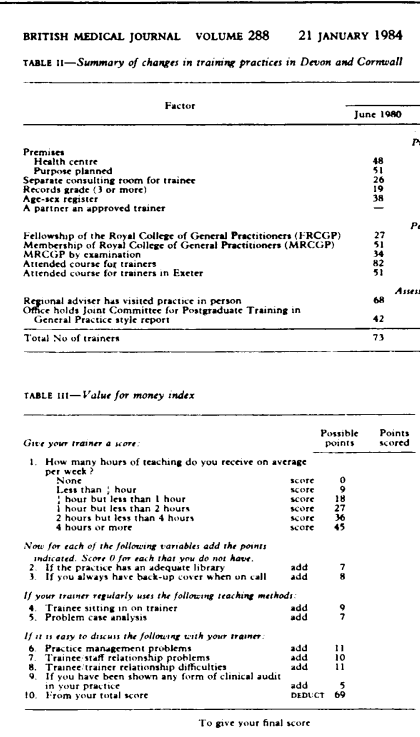

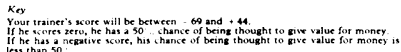

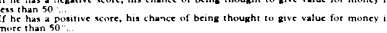

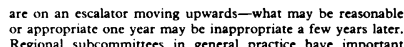

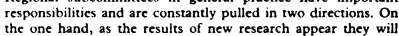

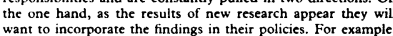

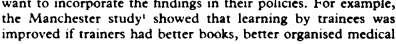
records, previous teaching experience, and were members of
the Royal College of Genereal Practitioners. On the other hand

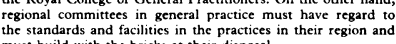
muss build with he bricks at their disposal.
In Devon and Cornuall in Junc 1980 only abour a third

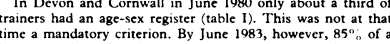

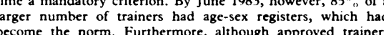

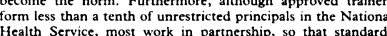
Actill
set by
regionional

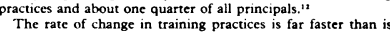

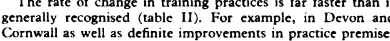

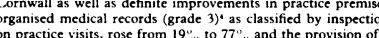

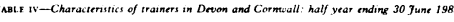

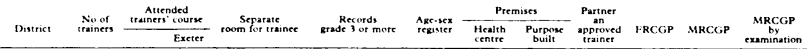

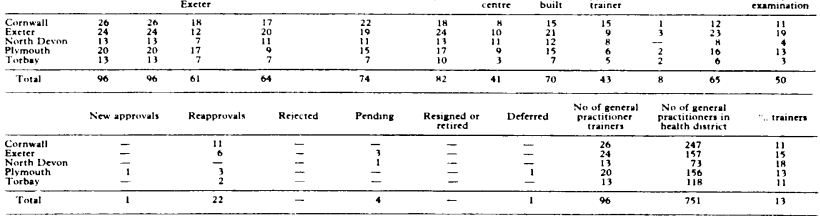

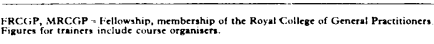

198

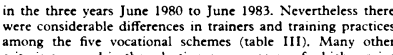
among the five vocational schemes (table III). Many tother
criteria are used in the selection process some of which receive greater emphasis in some regions chan others (table IV). There
is space herc only for the 10 listred above about whose importane Locking to the turutre, selection criteria and selection proce
dures are continuing to change. In the Midland region traines akec a written examination and in the Oxford region vider conclusion seems to be that the emphasis in sclection is moving
on frrom the physical or structural aspects of training practices the results of research clarify ye tactors associated with bette

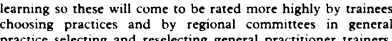

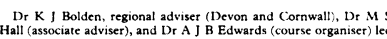

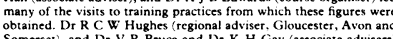

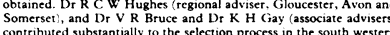

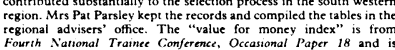

BRITISH MEDICAL JOURNAL VOLUME $288 \quad 21$ JANUARY 1984 reprod

References

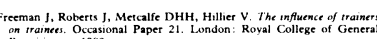

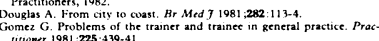

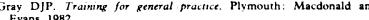

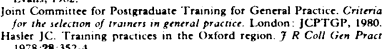

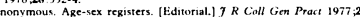

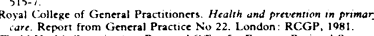

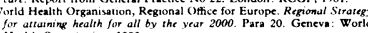

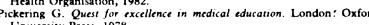

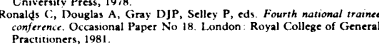

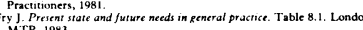

\section{Conference Report}

Reading the printout on the wall: decision making in general practice

PAUL HODGKIN

The Department of Industry scheme may have opened up the
the ioys-and soerows-of computing to many more general probably come as no surprise, however, to learn that the
computer wortd is eycing up the staid old world of general

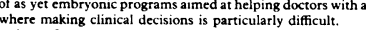

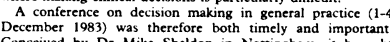

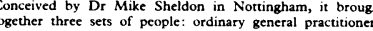

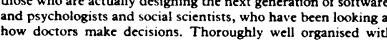

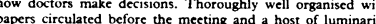

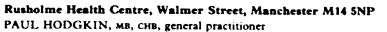

